\title{
Changes in trajectories of physical growth in a domestic adoptees sample: A preliminary study
}

\author{
Pietro Ferrara ${ }^{1,2}$, Costanza Cutrona ${ }^{2}$, Chiara Guadagno ${ }^{2}$, Maria Elisa Amodeo $^{2}$, Ester \\ Del-Vescovo ${ }^{2}$, Francesca Ianniello ${ }^{1}$, Tommasangelo Petitti ${ }^{3}$ \\ ${ }^{1}$ Institute of Pediatrics, Catholic University Medical School; ${ }^{2}$ Service of Pediatrics, Campus Bio-Medico University; ${ }^{3}$ Public \\ Health and Statistics, Campus Bio-Medico University, Rome ,Italy \\ E-mail pietro.ferrara@unicatt.it - p.ferrara@unicampus.it \\ Received: 12th July 2017, Revised: 16th August 2017, 18th September 2017, Accepted: 30th October 2017
}

SUMMARY: Ferrara P, Cutrona C, Guadagno C, Amodeo ME, Del-Vescovo E, Ianniello F, Petitti T. Changes in trajectories of physical growth in a domestic adoptees sample: A preliminary study. Turk J Pediatr 2018; 60: 464-466.

Internationally adopted infants experienced profound institutional deprivation in early infancy. Adoption may have a positive effect on child development, providing a massive catch-up growth in the developmental parameters.

In this preliminary study we examined the effect of family deprivation on abandoned children placed in high quality foster care during infancy. We also investigated the presence of a growth delay in Italian domestic adoptees at the time of family placement and the potential physical recovery after adoption.

Anthropometric measures (weight, length or height /head circumference) and Body Mass Index (BMI) were measured on arrival (T0) and 6 (T1), 12 (T2) and 24 months (T3) after adoption.

The results show moderate delays in physical growth on the children's arrival into the adoptive family and a significant catch-up growth in all auxological parameters from $T_{0}$ to $T_{3}$.

This is one of few Italian studies that points out a positive change in trajectories of growth after child adoption.

Key words: domestic adoptive families, growth delay, adopted children, catch up growth.

Several researches have focused on developmental outcome in internationally adopted infants who experienced profound institutional deprivation in early infancy. ${ }^{1}$ These children were severely developmentally impaired at the time of family placement, presenting delays in mental, social, and physical growth. ${ }^{2}$ Adoption may have a positive effect on child development, providing a massive catchup growth in the developmental parameters. ${ }^{3}$ The aims of our study are to investigate the presence of a growth delay in domestic adoptees at the time of family placement and to examine the degree of recovery at 6 th, 12 th and 24 th months after adoption in order to perform a global evaluation of physical growth in these children.

We evaluated 39 children adopted from January 2013 and October 2014, with the permission of the Juvenile Court of Rome. Both caregivers of each child provided their informed consent. This preliminary study was conducted in accordance with the regulatory standards of Good Clinical Practice and the Declaration of Helsinki (1996) and with the permission of Guarantor of the Child and Adolescent and of Lazio's Regional Council. Eighteen children $(46.2 \%)$ were males and $21(53.8 \%)$ females. There were $6(15.4 \%)$ adopted biologically related sibling pairs in our sample. Before adoption, all infants were placed in high quality foster care; the mean time spent in foster care was $16.25 \pm 26.18$ months (range $0.5-110$ ). Age at family placement was $8.25 \pm 8.99$ months. Excluding 6/39 domestic adoptees lost to follow-up, 33/39 children were investigated concerning body mass index (BMI) and anthropometric measures (weight, length/ height and head circumference) on arrival 
Table I. Anthropometric Measures at $\mathrm{T}_{0}, \mathrm{~T}_{1}, \mathrm{~T}_{2}$ and $\mathrm{T}_{3}(\mathrm{~N}=33)$.

\begin{tabular}{|c|c|c|c|c|}
\hline & Weight & Length/Height & Head circumference & Body mass Index \\
\hline $\mathrm{T}_{0}$ & -1.16 & -1.08 & -1.10 & -0.59 \\
\hline $\mathrm{T}_{1}$ & $\begin{array}{c}-0.34 \\
\left(\mathrm{p}<0.5 \quad \mathrm{~T}_{0}-\mathrm{T}_{1}\right)\end{array}$ & -0.58 & $\begin{array}{c}-0.21 \\
\left(\mathrm{p}<0.5 \mathrm{~T}_{0}-\mathrm{T}_{2}\right)\end{array}$ & $\begin{array}{c}0.11 \\
\left(\mathrm{p}<0.5 \mathrm{~T}_{0}-\mathrm{T}_{1}\right)\end{array}$ \\
\hline $\mathrm{T}_{2}$ & $\begin{array}{c}0.12 \\
\left(\mathrm{p}<0.5 \quad \mathrm{~T}_{0}-\mathrm{T}_{2}\right)\end{array}$ & $\begin{array}{ll} & -0.15 \\
(\mathrm{p}<0.5 & \left.\mathrm{T}_{0}-\mathrm{T}_{2}\right)\end{array}$ & $\begin{array}{ll}(\mathrm{p}<0.5 & \left.\mathrm{T}_{0}-\mathrm{T}_{2}\right) \\
(\mathrm{p}<0.5 & \left.\mathrm{T}_{1}-\mathrm{T}_{2}\right)\end{array}$ & $\begin{array}{c}0.27 \\
\left(\mathrm{p}<0.5 \quad \mathrm{~T}_{0}-\mathrm{T}_{2}\right) \\
1.09\end{array}$ \\
\hline $\mathrm{T}_{3}$ & $\begin{array}{c}0.22 \\
\left(\mathrm{p}<0.5 \mathrm{~T}_{0}-\mathrm{T}_{3}\right)\end{array}$ & -0.16 & & $\begin{array}{ll}(\mathrm{p}<0.5 & \left.\mathrm{T}_{0}-\mathrm{T}_{3}\right) \\
(\mathrm{p}<0.5 & \left.\mathrm{T}_{1}-\mathrm{T}_{3}\right)\end{array}$ \\
\hline
\end{tabular}

$\left(\mathrm{T}_{0}\right)$ and $6\left(\mathrm{~T}_{1}\right), 12\left(\mathrm{~T}_{2}\right)$ and 24 months $\left(\mathrm{T}_{3}\right)$ after adoption. Data were converted into $\mathrm{z}$ scores using Anthro statistical software. The comparison between anthropometric data at T0, T1, T2, T3 was performed using ANOVA for repeated measures and post-hoc Bonferroni test. Statistical significance is set at a nominal two-tail $\mathrm{P}<0.05$. Data on weight, length/height, head circumference and BMI at $\mathrm{T}_{0}, \mathrm{~T}_{1}, \mathrm{~T}_{2}$ and $\mathrm{T}_{3}$ are shown in Table I.

In regards to weight recovery process, we observed a statistically significant increase in weight $\mathrm{z}$ scores between $\mathrm{T}_{0}$ and $\mathrm{T}_{1}, \mathrm{~T}_{0}$ and $\mathrm{T}_{2}$, $\mathrm{T}_{0}$ and $\mathrm{T}_{3}(\mathrm{p}<0.05)$. With respect to length/ height catch-up, the only significant increase in median height $\mathrm{z}$ score was observed between $\mathrm{T}_{0}$ and $\mathrm{T}_{2}(\mathrm{p}<0.05)$. Regarding head circumference, we found a statistically significant difference in head circumference $z$ score between $T_{0}$ and $\mathrm{T}_{1}, \mathrm{~T}_{0}$ and $\mathrm{T}_{2}$ and $\mathrm{T}_{1}$ and $\mathrm{T}_{2}(\mathrm{p}<0.05)$. The increase in terms of BMI was already statistically significant between $T_{0}$ and $T_{1}$ and between, $T_{0}$ and $T_{2}, T_{0}$ and $T_{3}$, and from $T_{1}$ to $\mathrm{T}_{3}(\mathrm{p}<0.05)$.

We suppose that the growth delay observed in our sample was probably due to low birth weight (LBW). This condition is generally associated with several maternal risk factors, medical risks before or during gestation and unhealthy lifestyle. The large number of congenital anomalies detected in our experience (inter-ventricular septal defect, patent foramen ovale, club foot, spina bifida, congenital syphilis and HIV) suggests that biological mothers may had received inadequate prenatal care, resulting in LBW infants. ${ }^{4}$ Regarding weight, we found that catch-up was statistically significant already within the first 6 months after adoption, demonstrating a faster recovery than height. This result is congruent with evidence that weight gain is more dependent on recent food intake, while catch-up in height requires bone growth through the secretion of growth hormone. ${ }^{5}$

Several studies found substantial lags in anthropometric parameters in internationally adopted children at the time of adoption and showed that later age at arrival was related to less complete catch-up of height and weight. ${ }^{6}$ For what regards head circumference, previous researches about physical catch-up growth following severe early deprivation, demonstrate that the recovery process was incomplete. It suggests that brain size (and IQ) was more susceptible than height and weight to persisting deficits following profound institutional deprivation. ${ }^{7}$

Children adopted from orphanages were severely physically deprived because of malnutrition and neglect. ${ }^{8}$ Additionally, some researchers have concluded that cortisol curves of adopted children may differ from those of non-adopted. Particularly, the lack of sensitive care may lead to chronic stress and chronic activation of the Hypothalamic-Pituitary-Adrenal axis, that subsequently reduced appetite and suppressed growth hormones. ${ }^{9}$

According to other studies, it was found that not only Hypothalamic-Pituitary-Adrenal axis dis-regulation but also malnutrition, neurotrophic and neurotransmitter changes resulting from institutional deprivations can interfere with the plasticity of the developing brain. ${ }^{10,11}$ Conversely, we found a significant and complete catch-up in head circumference 6 months after family placement. It may indicate a more successful compensatory response, probably due to the fact that children of our sample didn't experience a deprived institutional 
rearing. Our findings are also consistent with a significant change in trajectories of growth after adoption. Discontinuity in care and relationships may have a negative impact on physical development of adopted children. Furthermore, stable and responsive caregiving may improve the social and psychological adjustment of adoptees, contributing to a physiological growth of children. ${ }^{12-14}$

In conclusion, pediatricians should be aware of special medical, mental and developmental needs, to help and assist adoptive families.

\section{REFERENCES}

1. Ferrara P, Romani L, Bottaro G, et al. The physical and mental health of children in foster care. Iran J Public Health 2013; 42: 368-373.

2. Rutter M, O'Connor TG; English and Romanian Adoptees (ERA) Study Team. Are there biological programming effects for psychological development? Findings from a study of Romanian adoptees. Dev Psychol 2004; 40: 81-94.

3. Gunnar MR, Bruce J, Grotevant HD. International adoption of institutionally reared children: Research and policy. Dev Psychopathol 2000; 12: 677-693.

4. Valero De Bernabé J, Soriano T, Albaladejo R, et al. Risk factors for low birth weight: A review. Eur J Obstet Gynecol Reprod Biol 2004; 116: 3-15.

5. Grotevant HD, McDermott JM. Adoption: Biological and social processes linked to adaptation. Annu Rev of Psychol 2014; 65: 235-265.
6. Van IJzendoorn MH, Bakermans-Kranenberg MJ, Juffer F. Plasticity of growth in height, weight, and head circumference: Meta-analytic evidence of massive catchup after international adoption. J Dev Behav Pediatr 2007; 28: 334-343.

7. Rutter M, Beckett C, Castle J, et al. Effects of profound early deprivation: An overview of findings from a UK longitudinal study of Romanian adoptees. Eur J Dev Psychol 2007; 4: 332-350.

8. Johnson DE. Adoption and effect on children's development. Early Hum Dev 2002; 68: 39-54.

9. Romero LM, Dickens MJ, Cyr NE. The Reactive Scope Model-a new model integrating homeostasis, allostasis, and stress. Horm Behav 2009; 55: 375-389.

10. Xiong F, Zhang L. Role of the hypothalamic-pituitaryadrenal axis in developmental programming of health and disease. Front Neuroendocrinol. 2013; 34: 27-46.

11. Smith SM, Vale WW. The role of the hypothalamic pituitary-adrenal axis in neuroendocrine responses to stress. Dialogues Clin Neurosci 2006; 8: 383-395.

12. Ferrara P, Vitelli O, Bottaro G, et al. Factitious disorders and Munchausen syndrome: The tip of the iceberg. J Child Health Care 2013; 17: 366-374.

13. Ferrara P, Corsello G, Sbordone A, Nigri L, Ehrich J, Pettoello-Mantovani M. Foster Care: A Fragile Reality Needing Social Attention, and Economic Investments. J Pediatr 2016; 173: 270-271.e1.

14. Ferrara P, Ianniello F, Cutrona, C, et al. A focus on recent cases of suicides among Italian children and adolescents and a review of literature. Ital J Pediatr. 2014; 40: 69 . 